\title{
Anti-Diabetic Effects of the Ethyl-Acetate Fraction of Trichilia catigua in Streptozo- tocin-Induced Type 1 Diabetic Rats
}

\author{
Rodrigo Mello Gomes ${ }^{a}$ Luis Fernando de Paulo \\ Cynthia Priscilla do Nascimento Bonato Panizzon ${ }^{c}$ Camila Quaglio Neves ${ }^{c}$ \\ Bruna Colombo Cordeiro ${ }^{c}$ Jacqueline Nelisis Zanonic Flávio Andrade Francisco ${ }^{d}$ \\ Silvano Piovan ${ }^{d}$ Paulo Cezar de Freitas Mathias ${ }^{d}$ Renata Longhinie \\ João Carlos Palazzo de Mello Júlio Cezar de Oliveira ${ }^{f}$ Gustavo Rodrigues Pedrinoa \\ Angela Adamski da Silva Reis ${ }^{g}$ Alessandra Lourenço Cecchini ${ }^{b}$ \\ Maria Raquel Marçal Natalic
}

\begin{abstract}
aDepartment of Physiological Sciences, Federal University of Goiás, Goiânia/GO, ${ }^{b}$ Department of General Pathology, State University of Londrina, Londrina, 'Department of Morphological Sciences, State University of Maringá, Maringá, 'Department of Cell Biology, State University of Maringá, Maringa, eLaboratory of Pharmaceutical Biology, Palafito, Maringá, Institute of Health Sciences, Federal University of Mato Grosso, Sinop, 9Department of Biochemistry, Federal University of Goiás, Goiânia/GO, Brazil
\end{abstract}

\section{Key Words}

Diabetes $•$ Nephropathy $•$ Pancreatic islets $\bullet \beta$-cell $•$ Antioxidants $\bullet$ Trichilia catigua

\begin{abstract}
Background/Aims: Trichilia catigua A. Juss., known as "catuaba" in Brazil, has been popularly used as a tonic for fatigue, impotence and memory deficits. Previously, our group demonstrated that the ethyl-acetate fraction (EAF) of T. catigua has antioxidant and anti-inflammatory effects. The present study evaluated the anti-diabetic activity of EAF in type 1 diabetic rats. Methods: Male Wistar rats were divided into four groups (N: non-diabetic group, D: type 1 diabetic group, NC: non-diabetic + EAF group and DC: type 1 diabetic + EAF group). The latter two groups were treated with $200 \mathrm{mg} / \mathrm{kg}$ EAF. Type 1 diabetes was induced by intravenous streptozotocin (STZ) injection (35 mg/kg). Starting two days after STZ injection, EAF was administered daily by gavage for 8 weeks. Results: EAF attenuated body mass loss and reduced food and water intake. EAF improved hyperglycaemia and other biochemical parameters, such as alkaline phosphatase (ALP), alanine aminotransferase (ALT) and aspartate aminotransferase (AST). Furthermore, the number of pancreatic $\beta$-cells and the size of the islets had increased by $\beta$-cell proliferation in the DC group. EAF promoted reduction in kidney tissue damage in STZinduced diabetic rats by reduction of renal fibrosis. Conclusion: The present study showed that EAF improves glucose homeostasis and endocrine pancreas morphology and inhibits the development of diabetic nephropathy in STZ-induced diabetic rats.
\end{abstract}




\section{Introduction}

Diabetes mellitus (DM) is a chronic non-communicable disease that results in chronic hyperglycaemia. Type $1 \mathrm{DM}$ is characterized by pancreatic $\beta$-cell apoptosis and massive reduction in the number and area of the pancreatic islets [1-3]. In 2015 alone, this pathology affected 415 million people worldwide, caused 5.0 million deaths and cost 673 billion dollars from public coffers worldwide [4].

Chronic hyperglycaemia leads to elevated production of advanced glycation end products (AGEs) and oxidative/inflammatory activities. In this way, DM is associated with tissue injuries leading to a risk of cardiometabolic diseases and their related complications as long-term consequences, which include ketoacidosis, neuropathy, retinopathy, cardiovascular disorders and nephropathy [5].

Natural products with antioxidant activity have been used for the treatment of DM and diabetic nephropathy [6-8]. In addition, polyphenolic compounds, flavonoids, tannins, anthocyanins and other phenolic constituents prevent oxidative damage and several degenerative diseases $[9,10]$. Trichilia catigua A. Juss., known as "catuaba" in Brazil, has been popularly used as a tonic for fatigue, impotence and memory deficits. It has been demonstrated that the ethyl-acetate fraction (EAF) of T. catigua has antioxidant and anti-inflammatory effects [10-12].

Previously, our group reported the antioxidant capacity of EAF from the bark of T. catigua, where nine polyphenolic constituents with antioxidant effects were found $[11,13]$. Furthermore, subchronic treatment with EAF promoted an antidepressant effect as well as increased hippocampal cell proliferation in mice [12]. In addition, T. catigua treatment provided significant neuroprotection in cerebral ischaemia-reperfusion, and this effect may be attributed to a reduction in reactive oxygen species (ROS) generation [14]. However, the protective mechanism of T. catigua against diabetes remains to be further clarified. Thus, considering the broad pharmacological effects attributed to T. catigua preparations, especially EAF, we hypothesize that EAF has potentially beneficial effects against type $1 \mathrm{DM}$, caused by pancreatic $\beta$-cell apoptosis, and its related complications such as nephropathy. In this study, we aimed to investigate the anti-diabetic effect of EAF from T. catigua and whether this preparation can attenuate the development of diabetic nephropathy in streptozotocin (STZ)-induced type 1 diabetic rats.

\section{Materials and Methods}

\section{Plant material and extract preparation}

The plant material and crude extract were prepared from the powdered bark of T. catigua as previously described [15]. The crude extract was dissolved in water, and EAF was isolated using an ethyl-acetate solution as previously described $[13,16]$.

The quality of the EAF was evaluated by measuring the amounts of procyanidin B2 (PB2) and epicatechin (EPC) in this fraction against analytical standards by HPLC analysis (Thermo ${ }^{\circledR}$, San Jose, CA, USA), according to a method developed and validated by our group, as previously described [16]. These standards were chosen for validation because they were available in the appropriate quantities at the laboratory. We solubilized $5 \mathrm{mg}$ of EAF in $3 \mathrm{~mL}$ of methanol-water solution (2:8; v/v) and then purified it with a solid-phase extraction cartridge (SPE, SampliQ C18, Agilent Technologies ${ }^{\circledR}$, Santa Clara, CA, USA) preconditioned with methanol and water. Subsequently, the samples were transferred to a volumetric flask, and the total volume was brought to $10 \mathrm{~mL}$ with methanol-water solution $(2: 8 ; \mathrm{v} / \mathrm{v})$. The samples were processed in triplicate.

Analysis was performed on an HPLC system with a photodiode array (PDA) spectrophotometric detector module (Model Finnigan Surveyor PDA Plus Detector), integral pumps and degasser (Finnigan Surveyor LC Pump Plus), and an auto sampler equipped with a $10 \mu \mathrm{L}$ loop (Finnigan Surveyor Autosampler Plus), and the process was controlled using ChromQuest software (Thermo ${ }^{\oplus}$, San Jose, CA, USA). The detection wavelength and flow rate were $280 \mathrm{~nm}$ and $0.4 \mathrm{~mL} / \mathrm{min}$, respectively. We used the Luna PFP(2) column model, $100 \AA \AA, 250 \times 4.6$ mm $5 \mu$ m (Phenomenex ${ }^{\circledast}$, Torrance, CA, USA), and a guard column $(6 \times 3$ mm, $5 \mu \mathrm{m}$; 


\section{Cellular Physiology Cell Physiol Biochem 2017;42:1087-1097 \\ \begin{tabular}{l|l} 
DOI: 10.1159/000478761 & $\begin{array}{l}\text { O 2017 The Author(s). Published by S. Karger AG, Basel } \\
\text { www.karger.com/cpb }\end{array}$
\end{tabular} \\ Gomes et al.: Anti-Diabetic Effects of Trichilia catigua}

Phenomenex $\left.{ }^{\circledR}\right)$. The mobile phase was eluted by a gradient system that consisted of Phase A, methanolacetonitrile (75:25; v/v), and Phase B, water, both containing 0.05\% trifluoroacetic acid (TFA), as follows: $0 \mathrm{~min}, 30 \%$ phase A; $36 \mathrm{~min}, 40 \%$ phase A; $38 \mathrm{~min}, 30 \%$ phase A, continued at $40 \mathrm{~min}$, followed by a $2 \mathrm{~min}$ post-time to re-equilibrate the system.

\section{Ethical approval}

The handling of experimental animals was in accordance with Brazilian Law no. 11.794/2008 and approved by The Animal Ethics Committee in Animal Research of the State University of Maringá (protocol number 082/2012).

\section{Animals and experimental design}

Adult male Wistar rats, aged 80 days, were housed in the animal facility of the Department of Morphological Sciences in polypropylene cages $(45 \mathrm{~cm} / 30 \mathrm{~cm} / 15 \mathrm{~cm}), 3$ animals per cage, under controlled luminosity [12:12 h light-dark cycle (06:00-18:00 h)] and temperature $\left(22.0 \pm 2{ }^{\circ} \mathrm{C}\right)$. All animals received standard chow (Nuvilab ${ }^{\circledR}$, Colombo, Paraná, Brazil) and water ad libitum. Food and water intake were evaluated daily, and body weight (BW) weekly.

After one week of adaptation, the animals were divided into four groups ( $n=12$ animals/group): (N) non-diabetic group, (D) type 1 diabetic group, (NC) non-diabetic + EAF group, and (DC) type 1 diabetic + EAF group.

\section{Induction of experimental diabetes}

Type 1 DM was induced by a single injection (35 mg/kg BW, i.v.) of STZ (Sigma-Aldrich, St. Louis, MO, USA) dissolved in citrate buffer $(0.1 \mathrm{~mol} / \mathrm{L}, \mathrm{pH} 4.5)$ into the penile vein, performed after overnight fasting and under anaesthesia (sodium thiopental; $40 \mathrm{mg} / \mathrm{kg} \mathrm{BW}$, i.p.). Diabetes was confirmed $48 \mathrm{~h}$ after STZ injection, and the animals that showed fasting blood glucose $>350 \mathrm{mg} / \mathrm{dL}$ were considered diabetic. Blood samples were obtained from a small cut in the tail vein and measured using a glucometer (ACCU-CHEK ${ }^{\circledR}$ Advantage, Roche Diagnostics, Mannheim, Germany).

\section{EAF treatment}

The animals from the NC and DC groups were treated daily with EAF orally administered by gastric gavage ( $200 \mathrm{mg} / \mathrm{kg}$ of BW) for 8 weeks. The EAF was diluted in a drop of glycerin and $0.9 \% \mathrm{NaCl}$ saline solution (100 mg of EAF in $1 \mathrm{~mL}$ of vehicle). The dilution was performed immediately prior to the treatment, and the volume administered was $2 \mathrm{~mL} / \mathrm{kg}$ of BW. Animals from non-treated groups received vehicle solution without EAF. The treatment occurred between 4:00 and 5:00 p.m.

\section{Euthanasia and sample collection}

At the end of the treatment period and after overnight fasting, the animals were anaesthetized with sodium thiopental (i.p. $40 \mathrm{mg} / \mathrm{kg} \mathrm{BW}$ ) for blood sample collection through cardiac puncture. Blood samples were collected into tubes without anticoagulant and centrifuged (3000 rpm for $5 \mathrm{~min}$ ), and the serum was stored at $-80^{\circ} \mathrm{C}$ for further analyses. Subsequently, the animals were euthanized, and samples of the soleus muscle, retroperitoneal and periepididymal adipose tissue, pancreas and left kidney were removed and weighed.

\section{Biochemical analysis}

Blood samples were used for measurement of blood glucose by the glucose oxidase technique (Gold Analisa ${ }^{\circledR}$ Belo Horizonte, Minas Gerais, Brazil) and of creatinine, uric acid, total protein, albumin, globulin, amylase, alkaline phosphatase (ALP), alanine aminotransferase (ALT), aspartate aminotransferase (AST) and gamma-glutamyl transferase (GGT) by enzymatic colorimetric methods (Gold Analisa ${ }^{\circledR}$ ) according to the manufacturer's instructions.

Histological analysis of the endocrine pancreas

Pancreas samples were fixed in 10\% buffered formalin, dehydrated, embedded in histological paraffin and sectioned $(5 \mu \mathrm{m})$ in non-serial cuts. The tissue sections were deparaffinized, rehydrated and blocked against endogenous peroxidase, washed in $0.01 \mathrm{~mol} / \mathrm{L}$ phosphate-buffered saline (PBS, pH 7.4) and incu- 
bated with $10 \%$ non-immune goat serum blocking solution (Histostain-Plus ${ }^{\circledast}$, Invitrogen, Carlsbad, CA, USA) for $10 \mathrm{~min}$. They were then incubated with monoclonal primary antibodies against insulin (1:500, Sigma $^{\circledR}$, St. Louis, MO, USA) or against PCNA (1:100, Zymed ${ }^{\circledR}$, San Francisco, CA, USA) for 60 min. After being washed $(0.01 \mathrm{~mol} / \mathrm{L} \mathrm{PBS})$, sections were incubated with a biotinylated secondary antibody (HistostainPlus $^{\circledast}$ ) for 10 min, washed and incubated with diaminobenzidine chromogenic solution (Histostain-Plus ${ }^{\circledast}$ ) for $15 \mathrm{~min}$, washed again, and finally counterstained with haematoxylin. The morphometric analyses were performed using digital images (TIFF 24-bit colour, $2560 \times 1920$ pixels) obtained with a light microscope (Olympus BX41, Tokyo, Japan) and a camera QColor 3 Olympus. Quantitative analyses of the islets number were performed using digital images ( $\times 20$ magnification) of 6 different fields from each animal $(n=6$ animals/group). Analyses of islet area, islet insulin immunodensity and PCNA-positive cells were performed using 40 digital images ( $\times 400$ magnification) from each animal ( $n=6$ animals/group). These analyses were performed using Image-Pro Plus 4.5 software (Media Cybernetics, Silver Spring, MD, USA).

Histological analysis of the kidney

Kidney samples were fixed in $10 \%$ buffered formalin, dehydrated and embedded in histological paraffin. Kidney tissues were sectioned $(5 \mu \mathrm{m})$ in non-serial cuts and stained with Heidenhain's Azan trichrome. The morphometric analyses were performed by measuring the positive collagen area in relation to the total area of digital images from the glomerular region of the kidney, using 40 digital images ( $\times 200$ magnification) from each animal ( $\mathrm{n}=6$ animals/group). These analyses were performed using Image-Pro Plus 4.5 software.

\section{Statistical analysis}

Data were expressed as the means \pm standard error (SEM). Significant differences between mean values of different groups were determined by one-way analysis of variance (ANOVA) with post hoc Tukey's tests. Differences were considered significant at $p<0.05$. Statistical analysis and graphs confection were performed using GraphPad Prism version 6.0 software for Windows (GraphPad Software Inc., San Diego, CA, USA).

\section{Results}

\section{Chromatographic analysis of EAF}

The chromatogram of EAF is shown in Fig. 1. The concentrations of PB2 and EPC in the EAF samples were $37.2 \pm 0.84$ and $20.3 \pm 0.74 \mu \mathrm{g} / \mathrm{mL}$, respectively. On the other hand, in the EAF analytical solution, the PB2 and EPC concentrations were 74.4 and $40.6 \mathrm{mg} / \mathrm{g}$, respectively.

\section{Effect of EAF from T. catigua on biometric parameters}

The STZ-diabetic rats showed low body weight throughout the experimental period compared to non-diabetic rats (Fig. 2A). This result is illustrated by their decrease in body weight gain (178\%; Fig. 2B). EAF treatment attenuated the body weight loss from the fifth to $8^{\text {th }}$ weeks of treatment in the DC group.

As shown in Fig. 2C and 2D, the retroperitoneal and periepididymal fat were decreased by approximately $94 \%$ in the STZ-diabetic group compared to non-diabetic rats. On the oth-

Fig. 1. HPLC analyses of EAF from T. catigua. Procyanidin B2 (PB2; $1)$, mixture of catechin and chlorogenic acid (2), cinchonain IIb (3), cinchonain IIa (4), epicatechin (EPC; 5), mixture of cinchonains Ia and $\mathrm{Ib}(6)$. Flow rate $0.4 \mathrm{~mL} / \mathrm{min}$, detection wavelength $280 \mathrm{~nm}$.

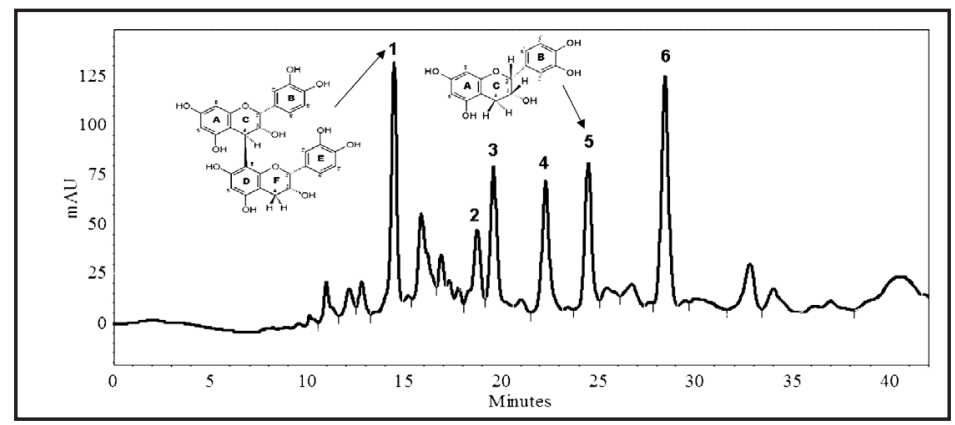


Fig. 2. Effect of EAF from T. catigua on biometric parameters. Body weight throughout experimental period (A), body weight gain (B), retroperitoneal adipose tissue (C), periepididymal adipose tissue (D) and soleus muscle (E) weight. Data are presented as the mean \pm SEM. One-way ANOVA and post hoc Tukey's test. N: non-diabetic group, D: type 1 diabetic group, NC: nondiabetic + EAF group and DC: type 1 diabetic + EAF group.
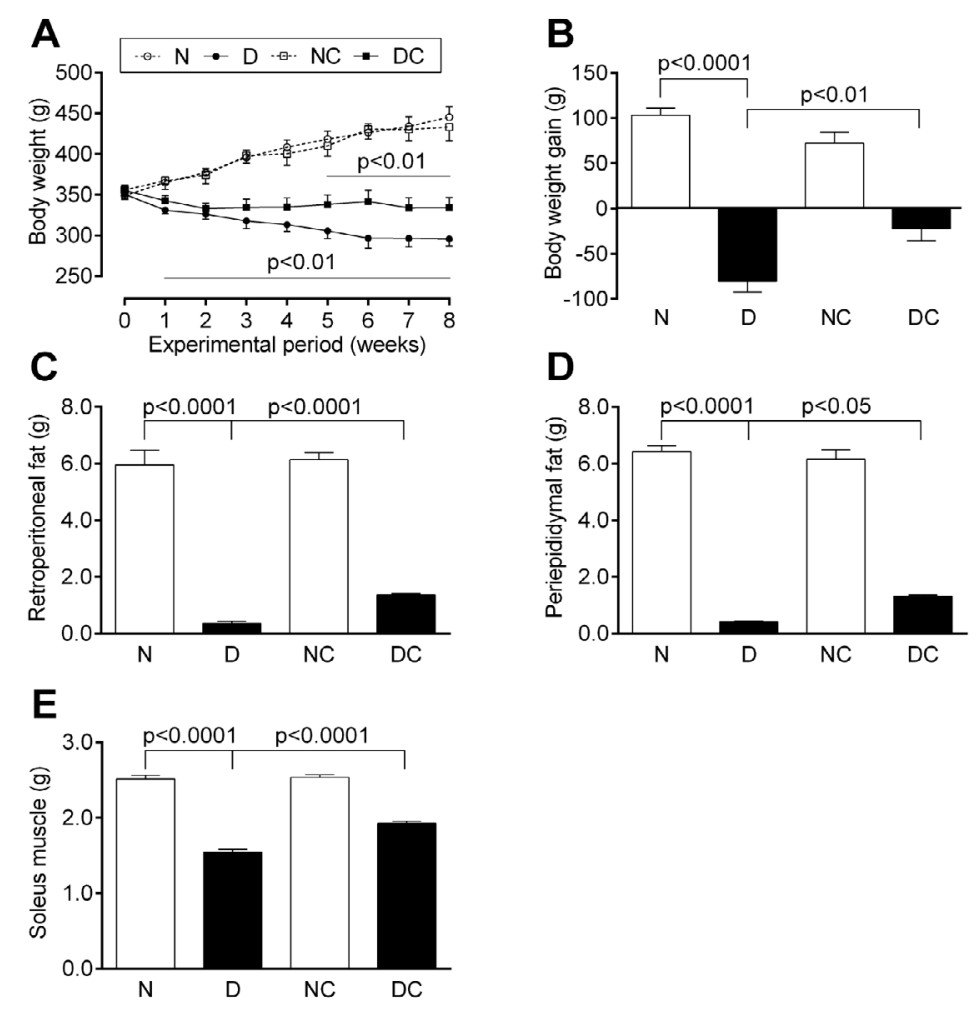

er hand, in the DC group, this fat weight loss was inhibited in both adipose tissue depots by EAF. The STZ-diabetic group had a reduction of 39\% in soleus muscle mass. However, EAF treatment inhibited this parameter by $25 \%$ in the DC group (Fig. 2E).

\section{Effect of EAF from T. catigua on food and water intake}

Figure 3 illustrate the effect of EAF on food and water intake. The non-diabetic groups (N and NC groups) show similar curves of food and water intake (Fig. 3A and 3C, respectively). STZ-diabetic rats show higher food and water intake throughout the experimental period compared to the control rats. The area under the curve (AUC) values of food and water intake increased by $64 \%$ and $361 \%$, respectively, in the STZ-diabetic group compared to the non-diabetic group (Fig. 3B and 3D, respectively). Interestingly, treatment with EAF attenuated the increase in food and water intake, reducing it by approximately $23 \%$ and $42 \%$, respectively, in the DC group.

\section{Effect of EAF from T. catigua on biochemical parameters}

Table 1 shows the effect of EAF on biochemical parameters. Blood glucose concentration was higher in STZ-diabetic rats compared to non-diabetic rats $(403 \% ; p<0.05)$. However, EAF treatment reduced significantly (24\%) blood glucose in DC group $(p<0.05)$.

STZ-diabetic rats exhibited low serum creatinine levels, and this parameter did not change in STZ-diabetic rats treated with EAF. On the other hand, serum levels of uric acid and amylase increased significantly in STZ-diabetic rats compared to non-diabetic rats $(p<$ 0.05). Nevertheless, EAF treatment improved these parameters in the DC group.

STZ-diabetic rats showed significant decreases in serum levels of total protein (19\%), albumin $(13 \%)$ and globulin (28\%). Oral treatment with EAF reversed these parameters in the DC group. Furthermore, ALP, AST, ALT and GGT were significantly increased in the serum of STZ-diabetic rats compared to control rats $(p<0.05)$. EAF treatment promoted a marked reduction in these enzymes in the DC group $(p<0.05)$. 


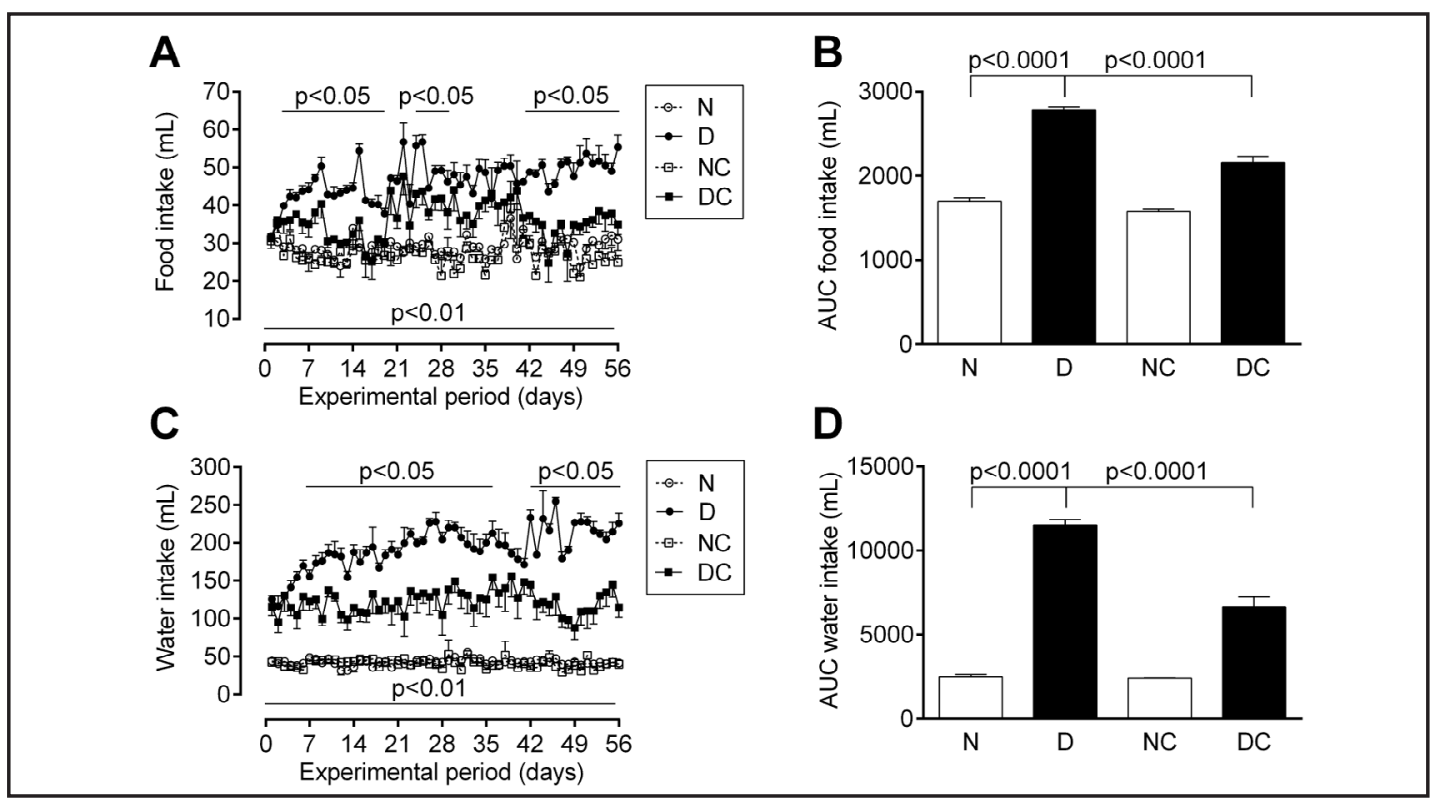

Fig. 3. Effect of EAF from T. catigua on food and water intake. Food intake throughout experimental period (A), AUC of food intake (B), water intake throughout experimental period (C) and AUC of water intake (B). Data are presented as the mean \pm SEM. One-way ANOVA and post hoc Tukey's test. N: non-diabetic group, D: type 1 diabetic group, NC: non-diabetic + EAF group and DC: type 1 diabetic + EAF group.

Table 1. Effect of EAF from T. catigua on biochemical parameters. Data are presented as the means \pm SEM. *values differ from non-diabetic group $(p<0.05)$, "values differ from diabetic group ( $\mathrm{p}<0.05)$ and $\mathrm{ns}$, not significantly different. One-way ANOVA and post hoc Tukey's test. N: non-diabetic group, D: type 1 diabetic group, NC: nondiabetic + EAF group and DC: type 1 diabetic + EAF group

\begin{tabular}{lcccc}
\hline & $\mathrm{N}$ & $\mathrm{D}$ & $\mathrm{NC}$ & $\mathrm{DC}$ \\
\hline Blood glucose (mg/dL) & $109.0 \pm 1.24$ & $547.9 \pm 13.21^{*}$ & $105.3 \pm 5.33$ & $414.6 \pm 34.87 \#$ \\
Creatinine (mg/dL) & $0.36 \pm 0.05$ & $0.20 \pm 0.02^{*}$ & $0.36 \pm 0.02$ & $0.25 \pm 0.02^{\mathrm{ns}}$ \\
Uric acid (mg/dL) & $50.86 \pm 2.82$ & $90.33 \pm 2.72^{*}$ & $48.00 \pm 1.53$ & $69.67 \pm 3.65^{\#}$ \\
Total protein (g/dL) & $5.71 \pm 0.05$ & $4.61 \pm 0.05^{*}$ & $5.76 \pm 0.10$ & $5.17 \pm 0.06^{\#}$ \\
Albumin (g/dL) & $2.81 \pm 0.03$ & $2.45 \pm 0.03^{*}$ & $2.80 \pm 0.11$ & $2.76 \pm 0.08^{\#}$ \\
Globulin (g/dL) & $2.91 \pm 0.03$ & $2.10 \pm 0.04^{*}$ & $2.93 \pm 0.04$ & $2.40 \pm 0.04^{\#}$ \\
Amylase (U/dL) & $91.6 \pm 2.16$ & $175.4 \pm 5.52^{*}$ & $93.1 \pm 1.64$ & $131.2 \pm 2.477^{\#}$ \\
ALP (U/L) & $138.6 \pm 7.69$ & $1078.3 \pm 15.86^{*}$ & $152.7 \pm 7.95$ & $759.4 \pm 26.23^{\#}$ \\
ALT (U/L) & $224.7 \pm 22.47$ & $658.3 \pm 65.85^{*}$ & $222.1 \pm 25.87$ & $419.1 \pm 67.10^{\#}$ \\
AST (U/L) & $494.0 \pm 44.83$ & $693.6 \pm 22.73^{*}$ & $366.4 \pm 61.96$ & $335.9 \pm 15.60^{\#}$ \\
GGT (U/L) & $11.57 \pm 1.0$ & $44.00 \pm 4.6^{*}$ & $12.29 \pm 1.5$ & $18.71 \pm 4.5^{\#}$ \\
\hline
\end{tabular}

\section{Effect of EAF from T. catigua on the morphology of the endocrine pancreas}

Histopathological examination of the endocrine pancreas revealed a large reduction in the number of pancreatic $\beta$-cells and in the size and number of pancreatic islets in the STZdiabetic group compared to the non-diabetic group (Fig. 4A-4H). Quantitative morphometric analysis reveals significant reductions in the number, area and insulin immunodensity of pancreatic islets. (Fig. 4I, 4J and 4K). Moreover, the pancreatic islets from the STZ-diabetic group show uneven distribution of pancreatic $\beta$-cells, as shown in Fig. 4F. Interestingly, EAF treatment significantly improved the number, area and insulin immunodensity of pancreatic islets in the DC group and did not change these parameters in the NC group (Fig. 4I, 4J and $4 \mathrm{~K})$. Figure 5 shows that EAF induced pancreatic $\beta$-cell proliferation (PCNA-positive cells) in both treated groups. 


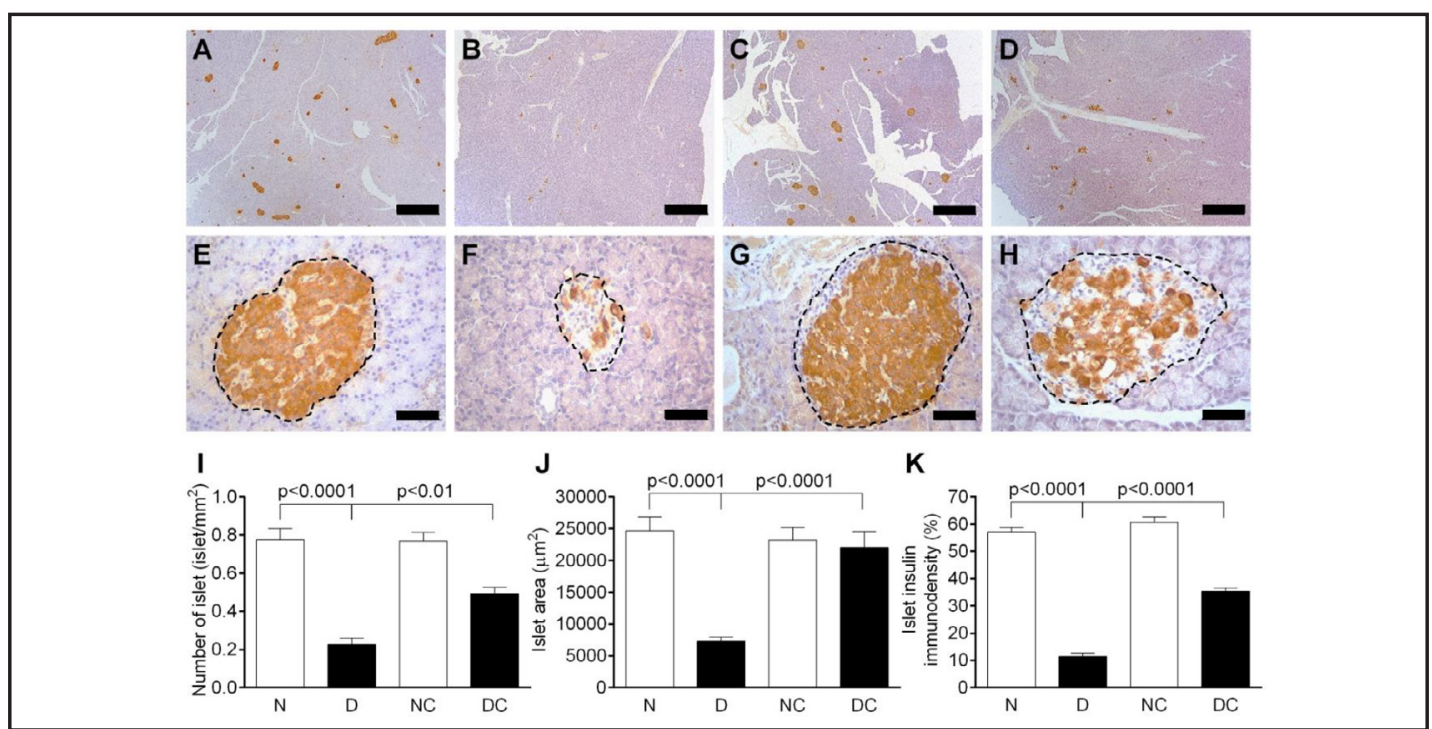

Fig. 4. Effect of EAF from T. catigua on morphology of endocrine pancreas. Representative photomicrographs $(A-D, \times 20$ magnification, scale bars $=1000 \mu \mathrm{m}$ and $\mathrm{E}-\mathrm{H}, \times 400$ magnification, scale bars $=50 \mu \mathrm{m})$ show pancreatic sections immunostained with anti-insulin antibody. Non-diabetic group (A and E), diabetic group (B and F), non-diabetic + EAF group ( $C$ and G) and diabetic + EAF group (D and H). Quantitative analysis is shown in (I), (J) and (K). Data are presented as the mean \pm SEM. One-way ANOVA and post hoc Tukey's test. N: non-diabetic group, D: type 1 diabetic group, NC: non-diabetic + EAF group and DC: type 1 diabetic + EAF group.

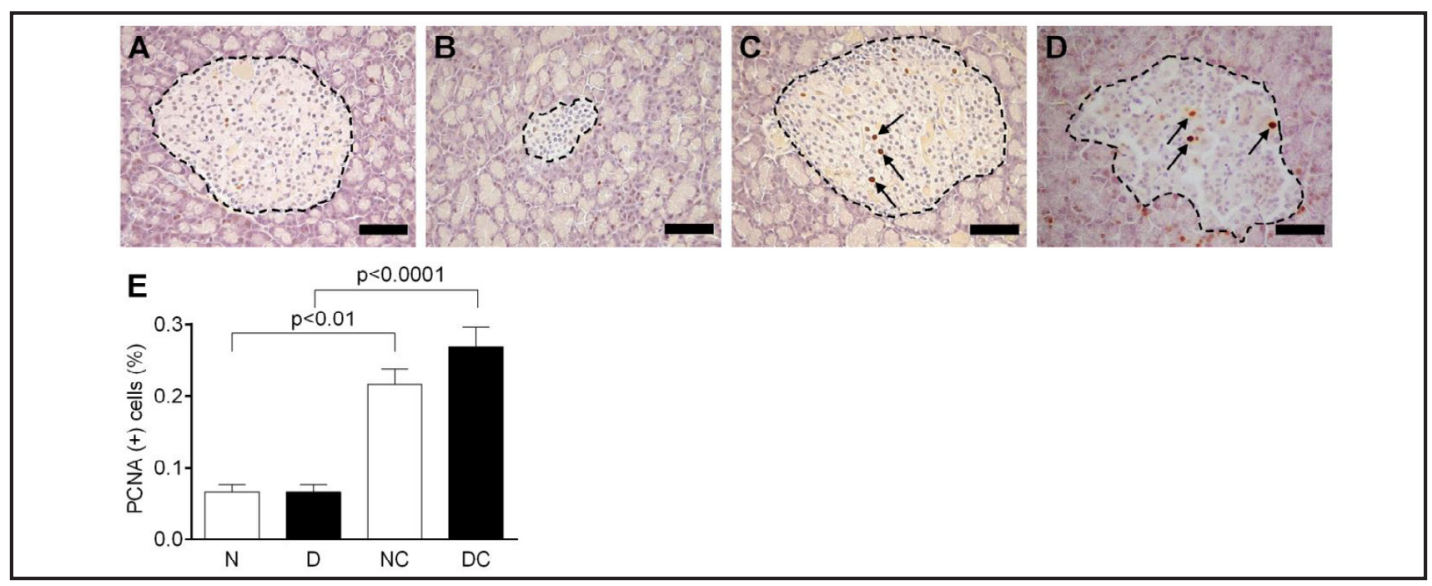

Fig. 5. Effect of EAF from T. catigua on cellular proliferation of endocrine pancreas. Representative photomicrographs $(A-D, \times 400$ magnification, scale bars $=50 \mu \mathrm{m})$ show pancreatic sections immunostained with anti-PCNA antibody. Non-diabetic group (A), diabetic group (B), non-diabetic + EAF group (C) and diabetic + EAF group (D). Images show nuclei immunolabelled for PCNA in the pancreatic islets of the $T$. catigua-treated groups (arrows). Quantitative analysis of the PCNA-positive cells (E). Data are presented as the mean \pm SEM. One-way ANOVA and post hoc Tukey's test. N: non-diabetic group, D: type 1 diabetic group, $\mathrm{NC}$ : non-diabetic + EAF group and DC: type 1 diabetic + EAF group.

\section{Effect of EAF from T. catigua on the morphology of the kidney}

As shown in Fig. 6E and 6F, both the absolute and relative weight of kidneys from STZdiabetic rats were significantly increased ( $21 \%$ and $96 \%$, respectively) compared to non-diabetic rats. In agreement with these data, as observed in Fig. 6B and 6G, the renal histopathological examination demonstrates a greater area of collagen in STZ-diabetic rats than in the control ones. Interestingly, these parameters were restored to normal by the EAF treatment. 


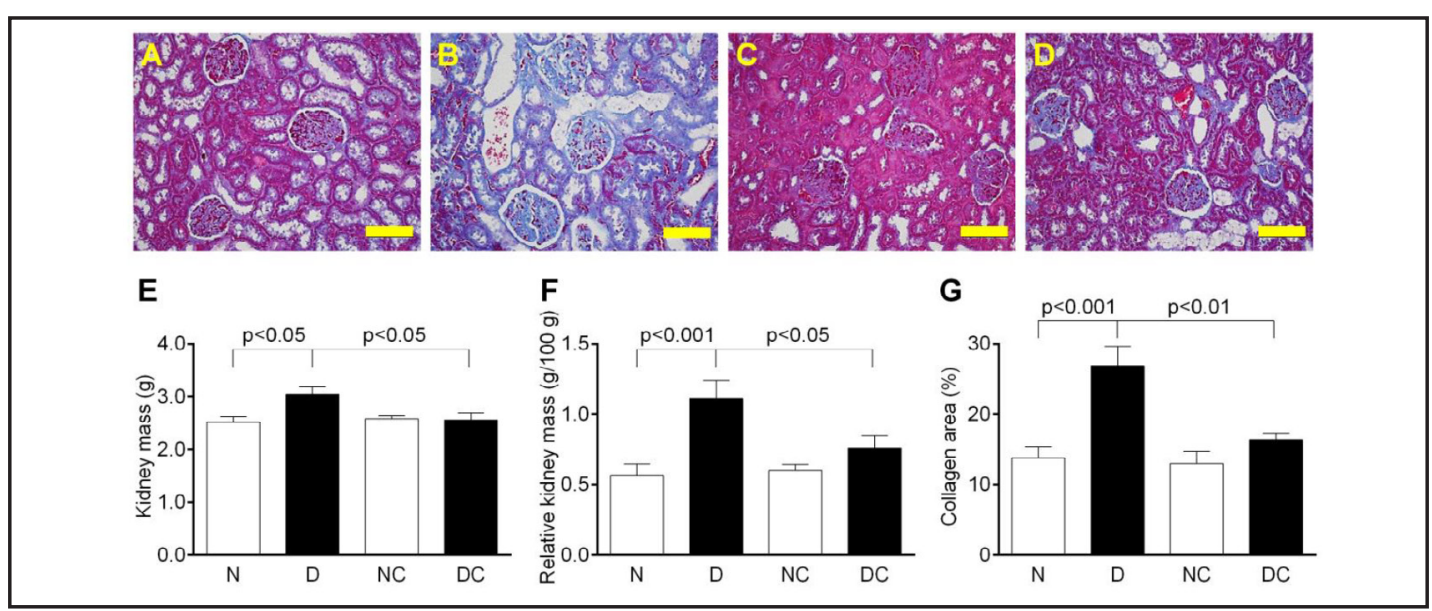

Fig. 6. Effect of EAF from T. catigua on morphology of kidney. Representative photomicrographs (A-D, $\times 200$ magnification, scale bars $=100 \mu \mathrm{m}$ ) show renal sections stained with Heidenhain's Azan trichrome. Nondiabetic group (A), diabetic group (B), non-diabetic + EAF group (C) and diabetic + EAF group (D). Kidney mass $(\mathrm{E})$, relative kidney mass $(\mathrm{F})$ and quantitative analysis of the collagen area $(\mathrm{G})$. Data are presented as the mean \pm SEM. One-way ANOVA and post hoc Tukey's test. N: non-diabetic group, D: type 1 diabetic group, $\mathrm{NC}$ : non-diabetic + EAF group and DC: type 1 diabetic + EAF group.

\section{Discussion}

The present study confirms the hypothesis that EAF treatment has an anti-diabetic effect. Given that, for the first time, this work shows that STZ-diabetic rats treated with EAF presented a significant attenuation in body weight loss as well as in the higher ingestion of food and water that features prominently in diabetes. Other studies observed that treatment with natural products improved these parameters $[17,18]$. Additionally, reduction of the blood glucose levels and an improvement in several others diabetic hallmark parameters were found herein. Furthermore, anti-insulin immunohistochemical analysis shows significant increased pancreatic $\beta$-cell number and islet size in the DC group as a result of $\beta$-cell proliferation, ascertained through labelling by PCNA immunohistochemistry. In addition, our histopathological studies showed that EAF promoted reduction in the kidney tissue damage that is caused by diabetes.

A striking feature of STZ-type 1 diabetic rats is a severe reduction of body weight caused by loss of adipose and muscular tissue; these characteristics are known as cachexia [19]. Adipose and muscular tissue need insulin signalling for glucose uptake; without insulin, these tissues show a significant reduction of glucose uptake that compromises their overall metabolism $[2,17]$.

The main therapeutic goal of diabetes treatment is to control blood glucose levels [4, 17]. Here, we show the effectiveness of the use of T. catigua as a powerful anti-diabetic agent, demonstrating improvements in the hyperglycaemia, polydipsia, and polyphagia observed in STZ-diabetic rats. In light of these results, new findings are needed for better understanding the hypoglycaemic effect of T. catigua. On the other hand, recent studies have shown antiinflammatory and antioxidant effects of PB2 and EPC, which exert positive effects by improving diabetes comorbidities. They were observed to bring improvement in insulin sensitivity and to exert a protective effect against diabetic nephropathy and cardiomyopathy [20,21].

In this study, diabetic animals exhibited low blood creatinine as well as decreased total protein, albumin and globulin levels compared to control animals. Interestingly, EAF treatment restored total protein, albumin and globulin concentrations nearly to control group values. No significant effect was observed in blood creatinine in the DC group. These results 
are consistent with improvement of diabetes and kidney function as observed in other studies $[18,22]$. Furthermore, previous studies have demonstrated lower serum creatinine levels and increased serum uric acid in STZ-diabetic animals and in type 2 diabetic humans [23]. Similarly, in this work, serum creatinine was lower and uric acid higher in the STZ-diabetic group, which could suggest renal impairments associated with diabetic complications [22]. Moreover, serum amylase was significantly elevated in STZ-diabetic rats, which is compatible with diabetic ketoacidosis [24]. However, we found that EAF attenuated diabetes-induced elevations in serum uric acid and amylase. Phenolic compounds present in T. catigua are probably, at least in part, the main agents responsible for the protective effect of EAF on kidney function as indicated by our results. In addition, previous studies have demonstrated that natural products exert protective effects on kidney function by mediating many of those parameters $[18,22,25]$.

The increases in the activity levels of serum ALP, ALT and AST enzymes have been associated with liver damage [26]. In the present study, a significant rise in the ALP, ALT, AST and GGT serum levels was observed in STZ-induced diabetic rats, whereas the diabetic group treated with EAF showed a significant improvement in these parameters. Several studies have shown that natural products from plants exert beneficial effects by reducing the high levels of ALP, ALT and AST in diabetic individuals, which leads an improvement in hepatic dysfunction [22, 26-28].

STZ-induced type 1 diabetes has been described as a useful experimental model for the study of diabetes because of the selective pancreatic $\beta$-cell destruction caused by this drug [29]. Here, we show a significant reduction in the number, area, and insulin immunodensity of pancreatic islets in STZ-diabetic rats that is compatible with pancreatic $\beta$-cell death caused by STZ. In particular, STZ induces the accumulation of superoxide, hydroxyl radicals and nitric oxide, which are known to be cytotoxic. Increased ROS production by STZ cause pore formation in mitochondria, resulting in disruption of the electrical potential of mitochondrial membrane, unbalancing pancreatic $\beta$-cell metabolism and insulin release $[30,31]$.

Interestingly, our hypothesis that EAF has anti-diabetic effects was confirmed by the findings shown in this study. Here, we depict the effectiveness of EAF treatment against diabetic complications; also, we suggest that the effects of EAF treatment in ameliorating diabetic injuries in STZ-diabetic rats may be closely associated with the increase of pancreatic $\beta$-cell proliferation as observed here, which partially restores the normal morphology and endocrine function of the damaged pancreatic islets caused by STZ in the rats. These findings indicate that EAF may be useful as a potential pharmacological agent to protect against pancreatic $\beta$-cell damage caused by oxidative stress associated with diabetes. However, the protective mechanism of EAF on pancreatic islets remains to be further clarified. We hypothesized that EAF has potentially beneficial effects against pancreatic $\beta$-cell apoptosis that may derive from its anti-inflammatory capacity and inhibitory actions against free radicals [13].

During the course of diabetes, hyperglycaemia induces AGE formation, pro-inflammatory cytokine overexpression and oxidative stress, promoting kidney damage [27, 32]. In the present study, STZ-diabetic rats show a large area stained by Azan trichrome, indicating ECM expansion and collagen deposition. This parameter is compatible with renal fibrosis. Thus, these results were compatible with the kidney function parameters such as low creatinine and serum protein and high uric acid found in this work. On the other hand, EAF treatment inhibited ECM expansion and restored renal morphology in the DC group to a normal pattern. Obviously, EAF treatment may have improved morphology and renal function due to reduction of blood glucose. However, beneficial effects on renal function promoted by plant compound treatment, likely because of beneficial effects of polyphenols on free radicals and inflammatory status, have been observed $[18,25]$. The present study showed that EAF from T. catigua improves glucose homeostasis and endocrine pancreas function and inhibits the development of diabetic nephropathy in STZ-induced type 1 diabetic rats. All together, these observations suggest that T. catigua could be useful as an anti-diabetic agent. 


\section{Cellular Physiology Cell Physiol Biochem 2017;42:1087-1097 \begin{tabular}{l|l} 
DOI: 10.1159/000478761 & O 2017 The Author(s). Published by S. Karger AG, Basel \\
www.karger.com/cpb
\end{tabular}}

Gomes et al.: Anti-Diabetic Effects of Trichilia catigua

\section{Fundings}

This work was funded by the Brazilian Foundation: Conselho Nacional de Desenvolvimento Científico e Tecnológico (CNPq), Coordenação de Aperfeiçoamento Pessoal de Nível Superior (CAPES), Paraná Science Foundation (Fundação Araucária).

\section{Acknowledgements}

All authors are grateful to Maria Euride Carlos Cancino, Maria dos Anjos Moreira Fortunato and Maria Ângela Moreira da Costa for technical assistance.

\section{Disclosure Statement}

The authors have no competing interests.

\section{References}

1 Soto C, Raya L, Juarez J, Perez J, Gonzalez I: Effect of Silymarin in Pdx-1 expression and the proliferation of pancreatic beta-cells in a pancreatectomy model. Phytomedicine 2014;21:233-239.

2 ADA: Diagnosis and classification of diabetes mellitus. Diabetes Care 2014;37:S81-90.

-3 Park SW, Choi SA, Yun JW, Choi JW: Alterations in pancreatic protein expression in STZ-induced diabetic rats and genetically diabetic mice in response to treatment with hypoglycemic dipeptide Cyclo (His-Pro). Cell Physiol Biochem 2012;29:603-616.

4 I.D.F.: IDF Diabetes Atlas, 7th, International Diabetes Federation, Brussels, Belgium, 2015. Wada J, Makino H: Inflammation and the pathogenesis of diabetic nephropathy. Clin Sci 2013;124:139-152. Li X, Wang L, Gao X, Li G, Cao H, Song D, Cai S, Liang T, Zhang B, Du G: Mechanisms of Protective Effect of Ramulus Mori Polysaccharides on Renal Injury in High-Fat Diet/Streptozotocin-Induced Diabetic Rats. Cell Physiol Biochem 2015;37:2125-2134.

7 Qiang G, Yang X, Shi L, Zhang H, Chen B, Zhao Y, Zu M, Zhou D, Guo J, Yang H, Zhang L, Du G: Antidiabetic Effect of Salvianolic Acid A on Diabetic Animal Models via AMPK Activation and Mitochondrial Regulation. Cell Physiol Biochem 2015;36:395-408.

-8 Chen T, Zheng LY, Xiao W, Gui D, Wang X, Wang N: Emodin ameliorates high glucose induced-podocyte epithelial-mesenchymal transition in-vitro and in-vivo. Cell Physiol Biochem 2015;35:1425-1436.

-9 Szkudelski T, Szkudelska K: Resveratrol and diabetes: from animal to human studies. Biochim Biophys Acta 2015;1852:1145-1154.

10 Lonni AA, Longhini R, Lopes GC, de Mello JC, Scarminio IS: Statistical mixture design selective extraction of compounds with antioxidant activity and total polyphenol content from Trichilia catigua. Analytica Chimica Acta 2012;719:57-60.

-11 Resende FO, Rodrigues E, Luftmann H, Petereit F, de Mello JCP: Phenylpropanoid Substituted Flavan-3-ols from Trichilia catigua and their In Vitro Antioxidative Activity. J Braz Chem Soc 2011;22:2087-2093.

-12 Bonassoli VT, Chassot JM, Longhini R, Milani H, Mello JCP, de Oliveira RMW: Subchronic administration of Trichilia catigua ethyl-acetate fraction promotes antidepressant-like effects and increases hippocampal cell proliferation in mice. J Ethnopharmacol 2012;143:179-184.

13 Chassot JM, Longhini R, Gazarini L, Mello JC, de Oliveira RM: Preclinical evaluation of Trichilia catigua extracts on the central nervous system of mice. J Ethnopharmacol 2011;137:1143-1148.

14 Kamdem JP, Waczuk EP, Kade IJ, Wagner C, Boligon AA, Athayde ML, Souza DO, Rocha JB: Catuaba (Trichilia catigua) prevents against oxidative damage induced by in vitro ischemia-reperfusion in rat hippocampal slices. Neurochem Res 2012;37:2826-2835.

15 Dos Santos AH, Ramos AC, Silveira KM, Kiss AC, Longhini R, Diniz A, de Mello JC, Gerardin DC: The exposure to Trichilia catigua (catuaba) crude extract impairs fertility of adult female rats but does not cause reproductive damage to male offspring. J Ethnopharmacol 2015;166:86-91. 


\section{Cellular Physiology Cell Physiol Biochem 2017;42:1087-1097 \begin{tabular}{l|l} 
DOI: 10.1159/000478761 & $\begin{array}{l}\text { O 2017 The Author(s). Published by S. Karger AG, Basel } \\
\text { www.karger.com/cpb }\end{array}$
\end{tabular} \\ Gomes et al.: Anti-Diabetic Effects of Trichilia catigua}

16 Longhini R, Klein T, Bruschi ML, da Silva WV, Jr., Rodrigues J, Lopes NP, de Mello JC: Development and validation studies for determination of phenylpropanoid-substituted flavan-3-ols in semipurified extract of Trichilia catigua by high-performance liquid chromatography with photodiode array detection. J Sep Sci 2013;36:1247-1254.

17 Guo C, Zhang C, Li L, Wang Z, Xiao W, Yang Z: Hypoglycemic and hypolipidemic effects of oxymatrine in highfat diet and streptozotocin-induced diabetic rats. Phytomedicine 2014;21:807-814.

18 Honore SM, Cabrera WM, Genta SB, Sanchez SS: Protective effect of yacon leaves decoction against early nephropathy in experimental diabetic rats. Food Chem Toxicol 2012;50:1704-1715.

-19 Yin XX, Zhang YD, Shen JP, Wu HW, Zhu X, Li LM, Qiu J, Jiang SJ, Zheng XG: Protective effects of bendazac lysine on early experimental diabetic nephropathy in rats. Acta Pharmacol Sin 2005;26:721-728.

20 Yin W, Li B, Li X, Yu F, Cai Q, Zhang Z, Cheng M, Gao H: Anti-inflammatory effects of grape seed procyanidin B2 on a diabetic pancreas. Food Funct 2015;6:3065-3071.

-21 Cremonini E, Bettaieb A, Haj FG, Fraga CG, Oteiza PI: (-)-Epicatechin improves insulin sensitivity in high fat diet-fed mice. Arch Biochem Biophys 2016;599:13-21.

22 Ibrahim MA, Islam MS: Anti-diabetic effects of the acetone fraction of Senna singueana stem bark in a type 2 diabetes rat model. J Ethnopharmacol 2014;153:392-399.

23 Hjelmesaeth J, Roislien J, Nordstrand N, Hofso D, Hager H, Hartmann A: Low serum creatinine is associated with type 2 diabetes in morbidly obese women and men: a cross-sectional study. BMC Endocr Disord 2010;10:6.

24 Huang D, Jiang Y, Chen W, Yao F, Huang G, Sun L: Evaluation of hypoglycemic effects of polyphenols and extracts from Penthorum chinense. J Ethnopharmacol 2015;163:256-263.

25 Zhang H, Zhao T, Gong Y, Dong X, Zhang W, Sun S, Wang H, Gu Y, Lu X, Yan M, Li P: Attenuation of diabetic nephropathy by Chaihuang-Yishen granule through anti-inflammatory mechanism in streptozotocin-induced rat model of diabetics. J Ethnopharmacol 2014;151:556-564.

-26 Murali R, Srinivasan S, Ashokkumar N: Antihyperglycemic effect of fraxetin on hepatic key enzymes of carbohydrate metabolism in streptozotocin-induced diabetic rats. Biochimie 2013;95:1848-1854.

27 Kim YS, Jung DH, Sohn E, Lee YM, Kim CS, Kim JS: Extract of Cassiae semen attenuates diabetic nephropathy via inhibition of advanced glycation end products accumulation in streptozotocin-induced diabetic rats. Phytomedicine 2014;21:734-739.

28 Lekshmi RK, Rajesh R, Mini S: Ethyl acetate fraction of Cissus quadrangularis stem ameliorates hyperglycaemia-mediated oxidative stress and suppresses inflammatory response in nicotinamide/streptozotocin induced type 2 diabetic rats. Phytomedicine 2015;22:952-960.

29 Deeds MC, Anderson JM, Armstrong AS, Gastineau DA, Hiddinga HJ, Jahangir A, Eberhardt NL, Kudva YC: Single dose streptozotocin-induced diabetes: considerations for study design in islet transplantation models. Lab Anim 2011;45:131-140.

-30 Raza H, Prabu SK, John A, Avadhani NG: Impaired mitochondrial respiratory functions and oxidative stress in streptozotocin-induced diabetic rats. Int J Mol Sci 2011;12:3133-3147.

-31 Karunakaran U, Park SJ, Jun do Y, Sim T, Park KG, Kim MO, Lee IK: Non-receptor tyrosine kinase inhibitors enhances beta-cell survival by suppressing the PKCdelta signal transduction pathway in streptozotocin-induced beta-cell apoptosis. Cell Signal 2015;27:1066-1074.

-32 Brownlee M: The pathobiology of diabetic complications: a unifying mechanism. Diabetes 2005;54:16151625. 